\title{
A guerra civil na Síria: breve olhar sobre Aleppo a partir de Hannah Arendt
}

\section{A civil war in Syria: a brief look on Aleppo from Hannah Arendt}

La guerra civil en la Siria: breve mirada sobre Aleppo a partir de Hannah Arendt

Moacyr Gomes de Arruda Júnior ${ }^{1}$ João Alberto Mendonça Silva² Josemar de Campos Maciel ${ }^{3}$

\section{${ }^{1}$ Bacharel em Filosofia pela Universidade Católica Dom Bosco (UCDB). E-mail: moacyr.junior@missaosalesiana.org.br, ORCID: http://orcid.org/0000-0002-0139-1520}

${ }^{2}$ Mestre em Desenvolvimento Local pela Universidade Católica Dom Bosco (UCDB), com dissertação voltada para as populações quilombolas do Estado de Mato Grosso do Sul. Graduado em Filosofia pela UCDB. Tem experiência na área de Filosofia, Antropologia das Populações Afro-Brasileiras e no Decrescimento

Sereno, com ênfase em Filosofia, Antropologia e Economia. E-mail: giambattista@gmail.com, ORCID: http://orcid.org/0000-0003-3167-9469

${ }^{3}$ Estágio pós-doutoral concluído (Estudos Culturais, EACH-USP) com o projeto "Hospitalidade e Desenvolvimento: Por uma Pequena Conversação". Doutor em Psicologia pela Pontifícia Universidade Católica de Campinas (PUC Minas). Mestre em Psicologia pela Universidade Católica Dom Bosco (UCDB); e em Teologia Sistemática pela Pontifícia Universidade Gregoriana (PUG), Roma. Graduado em Filosofia pelas Faculdades Unidas Católicas do Mato Grosso (FUCMT); e em Teologia pela PUG. Professor na UCDB, no Mestrado em Desenvolvimento Local, Programa Master em Desenvolvimento

Territorial Sustentável (Master STEDE) Erasmus Mundus/Erasmus Plus e Licenciatura em Filosofia. E-mail: maciel50334@yahoo.com.br, ORCID: http://orcid.org/0000-0001-8277-9422 
Resumo: Este artigo busca olhar a recente Guerra Civil Síria, em especial as situações ocorridas na cidade de Aleppo, em diálogo com a óptica de Hannah Arendt. A partir de literatura especializada, aponta-se para possíveis contribuições do pensamento arendtiano para a reflexão acerca da situação vivenciada pelo povo sírio. O trabalho se organiza em três momentos: 1. Exposição da Guerra Civil Síria em Aleppo; 2. Apresentação e exploração dos conceitos arendtianos que podem lançar luz sobre as situações; e 3. Retorno aos conceitos de Arendt refletidos à luz da Guerra Civil Síria, sobretudo em relação à dignidade humana e ao extermínio. Conclui-se que retomar tais conceitos facilita o enquadramento da reflexão sobre o ser humano como sujeito de direitos devido ao fato de sua existência, razão ignorada pelos que fazem a guerra ao aniquilarem a dignidade, ora transformando os massacres em dados estatísticos, ora ignorando completamente todas as mortes e destruições contínuas.

Palavras-chave: guerra civil; dignidade; extermínio; banalidade do mal.

\begin{abstract}
This paper looks at the current Syrian Civil War, in special the situations occurred in the city of Aleppo, through the political-philosophical view of Hannah Arendt. Starting from the assumption of philosophical reflection and using a relevant bibliographical revision, we turning back to the possible contribution of the Arendtian concepts into the reflection about the situation experienced by the Syrian people. This research is organized in three moments: 1. Exposition of the Syrian Civil War in Aleppo; 2. Presentation and understanding of the Arendtian concepts that can contribute here; and 3. Return to the concepts of Arendt reflected on the light of the Syrian Civil War, especially on the tangent to human dignity and extermination. It can be concluded that retaking such concepts makes possible to think of the human being as subject of rights by the simple fact of its existence, reason ignored by those who make the war by annihilating the dignity, sometimes transforming the massacres into statistical data, sometimes completely ignoring all the murders and continuous destructions.
\end{abstract}

Keywords: civil war; dignity; extermination; banality of evil.

Resumen: Este artículo busca mirar la reciente Guerra Civil Siria, en especial las situaciones ocurridas en la ciudad de Aleppo, mediante la óptica político-filosófica de Hannah Arendt. A partir del supuesto de la reflexividad filosófica y utilizando de revisión bibliográfica pertinente, se vuelve a esa posible contribución de los conceptos arendtianos para la reflexión acerca de la situación vivenciada por el pueblo sirio. Esta investigación se organiza en tres momentos: 1. Exposición de la Guerra Civil Siria en Aleppo; 2. Presentación y comprensión de los conceptos arendtianos que pueden contribuir; y 3. Retorno a los conceptos de Arendt reflejados a la luz de la Guerra Civil Siria, sobre todo en lo tangente a la dignidad humana y al exterminio. Se concluye que retomar tales conceptos posibilita un pensar en el ser humano como sujeto de derechos por el simple hecho de su existencia, razón ignorada por los que hacen la guerra al aniquilar la dignidad, ora transformando las masacres en datos estadísticos, ora ignorando completamente las muertes y destrucciones continuas.

Palabras clave: guerra civil dignidad; exterminio; banalidad del mal. 


\section{CONSIDERAÇÕES INICIAIS}

O texto que segue reflete sobre a guerra civil na Síria com atenção para atos e situações que mostram a degradação e violação do ser humano. A partir daí, aponta-se para a pergunta pela dignidade da pessoa humana em seu sentido mais pleno. Apropriando-nos de alguns conceitos e sugestões da abordagem filosófica de Hannah Arendt, buscamos uma clarificação das problemáticas dessa guerra, que, além de expor à brutal violência a população envolvida, tem mobilizado uma parcela mais sensível da humanidade. A intuição de fundo é a relação entre as violações na Síria e a sua repercussão para com toda a humanidade e a tarefa de se recuperar a dignidade humana fundamental, para além dessa banalização ostensiva.

A leitura dos fatos aqui proposta apenas acena para uma análise investigativa que visa enuclear conceitos sobre a condição humana, a partir de fatos reportados em relatórios do organismo "Anistia Internacional". A perspectiva de Hannah Arendt é suficientemente qualificada para mostrar que a banalização do mal segue ali em curso, com a banalização de um extermínio.

O pensamento de Hannah Arendt parte do pressuposto, que também é um corolário vazio, da dignidade irredutível do ser humano. Ou seja, pelo simples fato de existir, o ser humano é digno. Esse princípio é posto à prova em situações de crise e, no nosso caso, na Síria, o que se vê é o ser humano com a dignidade deletada, a existência exterminada sua pessoa reduzida à condição de objeto e à massificação.

Como se pode notar, a opção por refletir acerca de fatos, tentando encontrar pistas de interrogação filosófica, distingue-se como algo comum ao método fenomenológico na filosofia contemporânea. Nesse sentido, Arendt é uma boa indicação e professora, ensinando a resgatar significados por detrás de dimensões epiteliais de fatos.

\section{DO PROTESTO À GUERRA CIVIL}

As últimas notícias sobre a guerra na Síria são chocantes. O país se tornou velozmente o local de um colapso humanitário, a violência e o medo espalharam-se, produzindo insegurança. A crueldade desestabiliza o 
estado de direito e abre espaço para a degradação dos direitos humanos. Os meios mais comuns para isso são ataques aéreos, tiros e bombardeios. Especialistas contam as vítimas acima dos 400 mil mortos ou desaparecidos (DOUCET, 2018).

Os ataques violentos e sem piedade mobilizam opiniões e reações mesmo das pessoas mais distantes da política internacional. Essa guerra é uma catástrofe com potencial para destruição, mas também para espetáculo. Especialmente a cidade de Aleppo tem visto a sua população civil exposta a essas lesões que solapam a sua percepção e acesso à dignidade (ONU, 2017).

Localizada no leste da Síria, Aleppo é uma das maiores cidades do país e, nos últimos anos, vem sendo cenário de severos bombardeios e supliciada pelos enfrentamentos entre rebeldes e o regime sírio em combates que não parecem ter fim (DOUCET, 2018). Aleppo já foi o maior centro econômico da Síria e tornou-se Patrimônio da Humanidade em 1986, por obra da Unesco. Hoje, porém, anda arruinada, destruída por conta da violência. Observadores afirmam que não passa hoje de amontoados de destroços, cadáveres, refúgio dos sobreviventes e trincheira de rebeldes (AMNESTY INTERNATIONAL, 2015). Aleppo é uma cidade estratégica, tanto para as forças do governo sírio quanto para os rebeldes. Por conta de sua localização, Aleppo favorece aos rebeldes o acesso a armamentos e mantimentos e o seu controle é fundamental para aqueles se armarem, mas também para consolidar os interesses de controle do governo sírio.

Quando estourou a "Primavera Árabe", aquela onda de protestos e insurreições pró-democracia que ocorreu no Oriente Médio e Norte da África a partir do final de 2010, regimes autoritários estabelecidos da região foram mobilizados. A princípio, boa parte dos moradores de Aleppo se manteve fora de tais protestos. Confrontos envolveram "forças do governo e grupos de oposição armados surgiram na província de Aleppo em fevereiro de 2012" (AMNESTY INTERNATIONAL, 2015, p. 10, tradução nossa). Ainda assim, em Aleppo não tinham atingido grandes proporções como em outras localidades. As manifestações foram crescendo aos poucos e, em julho de 2012, os protestos ganharam escala. Rebeldes passaram a controlar parte da cidade, destruindo qualquer possibilidade de reabastecimento de armas e equipamentos por parte do governo. Há anos o governo sírio vem 
tentando, com insistência, recuperar a cidade e fechar o cerco contra os rebeldes (AMNESTY INTERNATIONAL, 2015).

Os conflitos em Aleppo envolvem o próprio regime sírio e a oposição ao regime do presidente Bashar al-Assad. Como apoiadores, ao lado do regime ditatorial sírio, estão a Rússia e alguns militantes xiitas do Hezbollah, estes subsidiados pelo Irã. Já como representantes da oposição estão milícias rebeldese outros grupos jihadistas que são coligados com a Al-Qaeda. O regime ditatorial sírio e os rebeldes possuem grupos relativamente fortes de apoiadores que se juntam para reforçar as frentes de destruição e defender os interesses particulares de cada uma das partes. Essa postura, se recorremos a Hannah Arendt (2008), não caracteriza uma atitude política. De acordo com ela, "a política se baseia no fato da pluralidade humana. Deus criou o homem, mas os homens são um produto humano, terreno, um produto da natureza humana" (ARENDT, 2008, p. 144). Logo, os homens são iguais e, como habitantes da terra, devem construir a relação intra-humana. É nesse espaço de pluralidade humana que se concretiza a política: cada ser humano, com suas particularidades, deve ser visto, ouvido, respeitado tratado com a dignidade devida (ARENDT, 2014). Desse modo, com os atos de desumanidade praticados nesta guerra, postulam a hipótese de que haja um retrocesso político em pleno curso.

Segundo o Relatório da Anistia Internacional, "pelo menos 18 grupos armados não estatais estão atualmente operando na cidade de Aleppo. Muitos desses grupos são compostos de subfacções e têm níveis variados de comando e controle" (AMNESTY INTERNATIONAL, 2015, p. 10, tradução nossa). Dessa maneira, a guerra na Síria, em sua expressão na cidade de Aleppo, vem perdurando por muito tempo e gerando grandes consequências de destruição e morte.

Um questionamento surge acerca da extensão temporal do conflito. Como ele perdura, visto que dentro da cidade sobram pouco mais de dez mil combatentes rebeldes, cercados por mais de quarenta mil combatentes do regime sírio (AMNESTY INTERNATIONAL, 2015)? A desproporção das forças envolvidas é discrepante. Ainda assim, os confrontos acontecem no interior da cidade, porque o grande temor de Assad é perder Aleppo. De fato, além de perder uma parte importante da Síria, também enfraqueceria grande parte de seu poder. 
O Estado sírio, muito interessado em dominar a cidade, e os rebeldes opositores ao regime desejosos de destronar o ditador, intensificam os bombardeios e os ataques aéreos, causando e agravando sofrimento para a população civil. Disse a Anistia Internacional que "ao longo da batalha por Aleppo, civis sofreram violações graves dos direitos humanos e do direito humanitário internacional" (AMNESTY INTERNATIONAL, 2015, p. 11, tradução nossa). A violência produzida pela explosão dos conflitos tem violado e ferido diariamente a dignidade humana dos civis que ainda resistem a se mudar dali. Das duas partes, percebe-se que: "a violência e a contraviolência envolvem-se num círculo vicioso mortal, engendrando cada uma delas as próprias forças que tentam combater" (ŽIŽEK, 2014, p. 73). Isto é, a morte produz mais morte, sem nenhuma razão e sem objetivos.

Centenas de civis que, de modo pacífico, manifestavam sua oposição ao governo, foram perseguidos, mortos ou mesmo desapareceram. Combatentes de milícias de oposição foram mortos sem piedade. Suas famílias foram dizimadas e suas casas completamente destruídas. Conforme o relatório, "forças do governo sírio iniciaram bombardeios aéreos de áreas controladas por forças da oposição na cidade de Aleppo e seu interior, usando armas como bombas de fragmentação banidas internacionalmente e mísseis balísticos de superfície" (AMNESTY INTERNATIONAL, 2015, p. 11, tradução nossa). As ações repressivas do governo ganharam uma proporção perturbadora: operações que se configuraram como crimes de guerra e abusos imensuráveis contra a humanidade desacreditaram a diversidade e negaram a pluralidade, que, como atesta Hannah Arendt, "[...] é a condição da ação humana" (ARENDT, 2014, p. 9). A devastação e a matança são de grande proporção e esses atos de destruição são executados contra um grupo nacional que se configura em um extermínio.

As forças do governo lançaram bombas contra escolas, hospitais, mesquitas e lugares de grande aglomeração civil. Em parte, tratava-se de bombas de barril, que contêm fragmentos de explosivos, barris de petróleo, gasolina, gás, estilhaços. Ou seja, tudo que puder explodir e ferir ou destruir. O relatório da Anistia prossegue confirmando: "Monitores locais disseram [...] que o grande número de vítimas civis é provavelmente devido ao fato de que as bombas de barris são tão imprecisas que o governo raramente 
as deixa perto da linha de frente, onde podem atingir suas próprias forças" (AMNESTY INTERNATIONAL, 2015, p. 20, tradução nossa). As bombas de barril são lançadas por helicópteros, ampliando o espectro de sua capacidade devastadora.

Após as explosões dos barris, aqueles que milagrosamente sobrevivem são obrigados a presenciar cenas de grande terror. Um sobrevivente de um dos ataques com bombas de barril na região de Aleppo disse à Anistia Internacional que viu "[...] pedaços de corpos e carros queimando com pessoas dentro. Casas também estavam queimando. Havia sangue por toda parte no chão" (AMNESTY INTERNATIONAL, 2015, p. 23, tradução nossa). Uma carnificina é presenciada por pessoas inocentes. O cenário de corpos espalhados por todos os lados, incluindo crianças, e amputações, segundo relatos, revela verdadeiro inferno (AMNESTY INTERNATIONAL, 2015). Os ataques foram, na maioria das vezes, contra a população civil, em lugares de grande aglomeração. Dessa maneira, constata-se que "as forças do governo de fato, deliberadamente, visaram civis e objetos civis. A segmentação deliberada de civis ou objetos civis é um crime de guerra" (AMNESTY INTERNATIONAL, 2015, p. 15, tradução nossa). O ímpeto de destruição e a frieza sem limites não têm levado em conta a presença das pessoas desesperadas, sendo assassinadas em suas próprias terras e moradias. Slavoj Žižek (2014), discorrendo sobre o assunto, oferece uma imagem conveniente para se pensar as vítimas dessa guerra. Segundo ele, "o sujeito torturado já não é um Próximo, mas um objeto cuja dor é neutralizada, reduzida a uma propriedade que pode ser gerida através de um cálculo utilitarista" (ŽlŽEK, 2014, p. 48).

Os atos de crueldade em Aleppo se manifestam com tanta frieza que revelam a condenação dos civis ao sofrimento e à perda da dignidade humana. E toda atitude de desumanidade efetuada se transforma em marcas profundas deixadas pela solidão e pela falta de amor (ŽIŽEK, 2014). Contudo, o regime sírio, quando se pronuncia oficialmente nos meios de comunicação, nega que em suas ações tenha utilizado qualquer tipo de armamento que denote crime. A situação dos munícipes de Aleppo é muito séria; durante os anos de conflito e bombardeios, são centenas de milhares de vítimas, incluindo muitas crianças e mulheres. 
Crimes de guerra e crimes contra a humanidade também são cometidos por parte dos grupos que se opõem ao regime, embora geralmente lutando com armas de menor alcance e calibre. Mas, ao utilizarem ocasionalmente armas de alcance impreciso, tais como foguetes improvisados, morteiros e canhões, os rebeldes também disseminam a morte e o terror entre os moradores de Aleppo. A grande variedade de grupos armados que aterrorizam a cidade, espalhando a morte e maus-tratos entre os civis, aumenta as violações de direitos humanos e a banalização do mal. Forçados a viver cotidianamente em situações desumanas, os civis já estão acostumados com a incidência da maldade em suas vidas. O povo de Aleppo, faminto e sem condição humanitária, vive uma contínua luta, tentando escapar dessa situação (AMNESTY INTERNATIONAL, 2015).

A população da cidade vive momentos terríveis de crueldade, suportando condições desumanas e ataques brutais. Vivendo em meio a escombros e em subsolos, os civis precisam, além de se proteger contra os bombardeios diários e devastadores, lutar para conseguir acesso ao essencial: água, alimentos, medicamentos. O Relatório da Anistia apresenta que "de acordo com residentes atuais e antigos de áreas controladas pela oposição na cidade de Aleppo, todos os dias há uma luta para atingir as necessidades mais básicas" (AMNESTY INTERNATIONAL, 2015, p. 48, tradução nossa). As necessidades sanitárias são aterrorizantes: lixo e esgotos estão por toda parte, entupidos e a céu aberto. Com a região em calamidade total, tudo fica mais caro e de difícil acesso. Uma opção tem sido o plantio de legumes; os moradores cultivam em qualquer lugar que estiverem. Alguns moradores também encontraram na criação de coelhos e gatos uma maneira de matar a fome de seus familiares: "Gatos e os coelhos são o fast food em Aleppo. Eles estão prontos para comer e não custam nada" (AMNESTY INTERNATIONAL, 2015, p. 49, tradução nossa).

Outra forma encontrada é fugir de determinadas regiões buscando lugares em que se pode ter um pouco mais de acesso ao essencial. Famílias desoladas deixaram o que restava de seus bens para escapar dos frequentes bombardeios e da terrível miséria. Muitos ainda permanecem em suas localidades, mesmo sem estrutura e com muita fome e pobreza, por falta de força ou por falta de outras opções. O povo sírio, de modo especial da região 
de Aleppo, vive sob efeito de medo, escondido e sem perspectiva (AMNESTY INTERNATIONAL, 2015). Sem o respeito e sem as condições básicas de sobrevivência, a dignidade humana vai sendo extirpada do povo sírio. Um povo que está vulnerável e fadado ao sofrimento até que os perpetradores de todas as desumanidades sejam tocados ou impedidos de algum modo.

\section{ALGUNS CONCEITOS-CHAVE}

O pensamento de Hannah Arendt mostra uma surpreendente atualidade em relação aos acontecimentos políticos do século XX. Foram vários os episódios que provocaram as suas reflexões no fim da década de 1960. Ao refletir a respeito da violência, Arendt estimula um repensar político que, em tempos modernos, experimenta frieza e desconfiança, sendo evidenciado e valorizado somente quando se visa a uma administração de interesses privados. Para se aprofundar verdadeiramente, é necessário saber sobre o poder, que, para Arendt, refere-se à constituição política no que tange à legitimidade e à autoridade.

Na política, a violência se fundamenta e se iguala ao poder quando passa a ser levada a cabo com comandos e obediências, desencadeando a supremacia do Homem sobre outro Homem (ARENDT, 2009). A violência é parte integrante e essencial na efetivação e manutenção do poder. No entanto, nos cenários mais diversos de conflito e dominação, é evidente que, para salvaguardar e manter o poder sem abalos, faz-se uso da violência, que é encarada como uma última opção e garantia de sucesso contra os opositores. Quando um poder se serve do uso da força, ele se torna contrário a todo e qualquer pensamento político (ŽIŽEK, 2014).

A violência empregada ou sustenta e estabelece o poder ou o enfraquece e o derrota (ARENDT, 2009). Para ela, o poder é a predisposição de ação conjunta das pessoas, rejeitando toda e qualquer relação entre poder e violência, desbancando, assim, a essencialidade de tal conjuntura para a constituição do domínio público. Testemunhamos, na contemporaneidade, exemplos de um uso exacerbado e descontrolado de um falso poder e do emprego funesto da violência, geradora de guerras civis, governos totalitários, populações sendo aniquiladas e armamentos de destruição sendo aprimorados. 
A guerra é potencialmente a consubstanciação da covarde e inútil violência. Com a fabricação e o uso de bombas, explosivos e armas químicas, a guerra tem se tornado um evento sem sentido que busca, sob a aparência de vitória, a produção da morte e o extermínio dos oponentes (ARENDT, 2009). O poder evocado pela violência ocasiona destruição e fomenta a rivalidade entre os homens. Esse clima hostil de rivalidade afeta e prejudica diretamente as famílias e compromete a sociedade, que é composta e mantida por muitas destas genealogias (ARISTÓTELES, 2006).

Na realidade pós-Segunda Guerra Mundial e na reprovação notória dos totalitarismos, encaminha-se o uso do termo extermínio para elucidar o evento sócio-político de erradicação de grupos sociais nas sociedades modernas (CRUZ-NETO; MINAYO, 1994). Entre as ações cometidas, compreende: o assassinato de membros de um grupo específico, qualquer dano grave à sua integridade física ou mental, a submissão de seus membros a condições de existência que proporcionem sua destruição física total ou parcial, qualquer ato que impeça os nascimentos dentro desse grupo e a transferência forçada de menores desse grupo a outro.

Como fundamentos do ato de extermínio estão o Estado e os governantes que se apresentam como agentes gerenciadores, negligenciadores, manipuladores e impossibilitadores de um julgamento mais eficaz aos atos violentos cometidos por seus executores. As classes menos favorecidas se instalam como vítimas; grupos tratados como generalização, vistos e tratados como massa, penalizada em grande escala. Há o esquecimento de que "somos iguais, isto é, humanos, de um modo tal que ninguém jamais é igual a qualquer outro que viveu, vive e viverá" (ARENDT, 2014, p. 10).

Para colocar em prática o objetivo central do extermínio, que é a destruição ou erradicação de um grupo subjugado, o governo se serve de estratégias fortes, estruturadas, organizadas e sempre com o intuito de extirpar grupos que não coadunam com o sistema e/ou civis que não se envolvem, mas acabam sendo penalizados pelos interesses funestos das partes envolvidas (KERSHAW, 2016). Tal temática não é um simples acontecimento de morte que se restringe a uma determinada nação, mas é um ato criminoso em oposição a um grupo nacional, étnico, racial ou religioso, 
um crime que fere o mundo inteiro e é contra a humanidade, pois nega a cada nação sua especificidade, sua diversidade e sua pluralidade:

Com efeito, a possibilidade e a intencionalidade de exterminar grupos étnicos, nacionais, religiosos ou raciais - [...] vale dizer, a aspiração de fazer desaparecer da face da terra um grupo, antes de ser um delito que fere os direitos das minorias é um crime contra a humanidade e a ordem internacional [...] porque visa eliminar a diversidade e a pluralidade que caracterizam o gênero humano (LAFER, 2003, p. 183).

De acordo com Hannah Arendt, o crime contra a humanidade se configura pela negação da pluralidade que fundamenta a condição humana. Esta pluralidade seria importante, pois enriquece a própria experiência da humanidade. Sem a pluralidade, o significado da própria palavra se esvazia (ARENDT, 2014). Dados históricos, explorados por lan Kershaw (2016), revelam que as principais características da dinâmica de extermínio podem ser vistas com clareza no nazismo, que assinalou o século XX com o horror absoluto. Isso fica mais claro quando Hannah Arendt discorre sobre tal realidade, no livro "Origens do Totalitarismo", ao afirmar que:

Os nazistas iniciaram o extermínio dos judeus, primeiro privando-os de um status legal (o status de cidadania de segunda classe) e cortando-os do mundo dos vivos, reunindo-os em guetos e campos de concentração; e antes de colocarem as câmaras de gás em movimento, eles tinham cuidadosamente testado o solo e descobriram, para sua satisfação, que nenhum país reivindicaria essas pessoas. A questão é que foi criada uma condição de inutilidade perfeita antes que o direito de viver fosse desafiado (ARENDT, 2004, p. 375).

Para o nazismo, inevitavelmente os judeus eram tratados como refugo por não possuírem as características defendidas como "raça pura"1 . O extermínio é a mais grave violação aos direitos humanos e a privação ao direito e à dignidade humana. Tal privação nada mais é do que tipificar a pessoa como um "ninguém", como um ser vulnerável que pode ser destruído a

\footnotetext{
1 "Raça pura" foi um termo criado no final do século XIX, utilizado, principalmente nos meios da Antropometria, para nomear e identificar os sujeitos de origem europeia. Hitler e o nazismo se apropriaram do termo, forçando a valorização dos arianos como se fossem mais puros. Obviamente, fomentando, assim, o descarte e o extermínio dos que os incomodavam.
} 
qualquer momento e que não precisa de muito tempo. De fato, a base da sua vida já foi removida, com o direito e a dignidade. O extermínio é o ato de grupos que dominam e se consideram detentores do poder de selecionar camadas da sociedade a serem extirpadas.

Para Arendt, a substituição do ser humano pela máquina tem origem no período histórico da Revolução Industrial. Com a imitação das atividades naturais, elas deixam de ser instrumentos e passam a ser o fim. Desde então, o ser humano principiou a instrumentalização da natureza, incluindo a da própria pessoa humana; não apenas se serve do que a natureza dispõe. Vai burlando e matando o processo natural, como era já presente na obra humana, mas agora se deixa guiar e conduzir pela máquina, pensando e agindo de acordo com as demandas da dinâmica de produção (ARENDT, 2014). Com essa instrumentalização, na qual reina a extinção e a falsificação do natural, tudo perde o valor, tudo perde a dignidade.

Nos regimes totalitários do século XX, esse movimento se estende aos seres humanos, que passam a ser encarados como instrumentos. O nazismo, com a retórica da "raça pura", usava como meio a eliminação de todos os que não se encaixavam nas exigências e nos padrões estabelecidos, ou seja, o ser humano foi encarado como mera "coisa" descartada quando, ou se, as finalidades assim exigiram. Arendt, retomando Kant (2005), defende que "nenhum homem pode jamais tornar-se um meio para um fim, todo ser humano é um fim em si mesmo" (ARENDT, 2014, p. 194). Logo, o sujeito não pode ser usado como instrumento e em nenhum momento poder ter sua dignidade retirada.

Com a instrumentalização do ser humano como "coisa", ele se torna mais manipulável e pode ser descartado de acordo com os interesses daqueles que detêm o poder. Por isso, para Arendt, o mal se banaliza. Lá onde o sujeito é destituído de sua racionalidade e é tomado como objeto, reificado ou coisificado, ele está mais propenso, mais vulnerável a realizar e sofrer o mal e a acostumar-se com isso. O sujeito se torna um número, uma unidade da massa sem personalidade, um ente "à mão", manipulável e do qual a eliminação não diz respeito a ninguém, pois não há quem chore por seu cadáver.

O mal, segundo Arendt (1999), sempre esteve em um lugar de destaque na história, sempre existiu e sempre existirá em meio a uma sociedade 
que trata o outro como um adversário ou até mesmo como um qualquer sem importância. O que predomina é a maldade e a "ideia de ódio puro e primitivo" (ŽlŽEK, 2013, p. 49). O mal é encarado como uma realidade irracional, primitiva, porque, mesmo sendo posteriormente teorizado, pode ser movido por meros sentimentos e vontades, como talvez sucedeu a Hitler no contexto do regime nazista em relação ao povo judeu. Tal maldade, com profundidade parecida, aparece na Guerra Civil Síria. Pessoas inocentes são expostas e sujeitadas a ataques monstruosos e não percebemos nos perpetradores nenhuma preocupação com a vida e com a dignidade dos civis que, sem oferecer perigo, são dizimados.

A dignidade humana, na situação da guerra síria, tem sua sacralidade profanada e até mesmo extirpada quando, de modo severo, são efetivadas as reações de maldade sem precedentes. Crianças, mulheres e idosos são os mais atingidos pelo mal que, sem pensar e sem planejar, fere e subtrai vidas inocentes. O governo, os rebeldes e todos os que financiam interesses diversos no conflito civil na Síria, sem sinal algum de dor na consciência e de modo muito tranquilo, atacam com a finalidade notória de socializar o mal que aterroriza a todos (ARENDT, 1999). Essa postura corrobora a noção arendtiana de que o mal é algo banal, ou seja, que pode ser praticado por qualquer ser humano e sem nenhuma fundamentação ou argumentação pertinente.

Em "Eichmann em Jerusalém", Arendt retrata o julgamento do oficial nazista Adolf Eichmann e se vale dessa personagem para apresentar a sua leitura da banalidade do mal. Isso pela sua surpresa ao ver, durante o julgamento, que a postura de Adolph Eichmann era convencional e normal. "O problema de Eichmann era exatamente que muitos eram como ele, e muitos não eram nem pervertidos, nem sádicos, mas eram e ainda são terrível e assustadoramente normais" (ARENDT, 1999, p. 299). Mesmo sendo incriminado por atos desumanos, de crueldade sem precedentes, ele possuía um perfil de funcionário burocrático e cumpridor de ordens. Ele mesmo, medíocre como parecia, talvez jamais fosse capaz de arquitetar e concluir tais atrocidades. Arendt se deixou convencer por um de seus argumentos: "Não sou o monstro que fazem de mim. Sou uma vítima da falácia" (ARENDT, 1999, p. 269). O problema que a humanidade deve discutir e retomar sempre 
é a natureza dessa falácia. Não se trata de algo simples, mas Arendt aponta para a necessidade de voltarmos a sentir e a nos indignar diante do mal e do absurdo. O caso de Eichmann mostra que, segundo Arendt, o mal se torna banal porque pode ser realizado por qualquer ser humano, em quaisquer realidades, mesmo que o sujeito não tenha a intenção clara nem uma consciência explícita de que está optando pelo mal. O mesmo ser humano que aperta parafusos e preenche planilhas obedecendo a sistemas cegos e sem refletir é muito capaz de produzir o mal absoluto, quando abre mão de valores em detrimento da conformidade heterônoma ao contexto e a suas exigências de padronização.

A grande preocupação de Hannah Arendt foi refletir acerca do valor e da dignidade do ser humano. Seu objetivo era, a partir de uma busca filosófica, fazer a sociedade repensar a pessoa e promover o respeito pela vida. Sendo judia, ela vivenciou os horrores da Segunda Guerra Mundial e teorizou sobre a ideia do mal encarnado de forma tecnológica, limpa, sem sensibilidade e perfeita, executado com precisão. Esse trabalho coagula-se em conceitos como poder, violência, extermínio, banalidade do mal e outros, sempre buscando recuperar a profundidade da indisponível dignidade humana. Retomar a filosofia arendtiana permite pensar com mais seriedade e embasamento crítico a existência humana e seus múltiplos desdobramentos.

Os conceitos de Hannah Arendt podem ser encarados como importantes e de grande ajuda para enquadrar teoricamente a situação vivenciada na guerra síria. O conflito armado em curso apresenta traços de produção de esfacelamento da dignidade humana, destruição do espaço público e degradação. Por outro lado, a tragédia mais durável não é apenas essa miséria material, mas a sua banalização, que pode levar a uma replicação mais trágica ainda.

\section{OS PRESSUPOSTOS DA GUERRA: INSTRUMENTALIZAÇÃO E BANALIDADE}

Após a leitura dos Relatórios da Anistia Internacional, podemos refletir com Hannah Arendt as questões que ferem tanto a dignidade dos civis sírios quanto daqueles diretamente envolvidos no conflito, que são os rebeldes e 
seus aliados e o governo sírio e seus apoiadores (AMNESTY INTERNATIONAL, 2015). A guerra síria, com os confrontos intermináveis, ganhou uma proporção descomunal e tem não só aterrorizado os civis residentes nos campos de fogo cruzado, mas também toda a população internacional (DOUCET, 2018). Desumanidades, monstruosidades, destroços e muitas outras palavras são utilizadas pelos meios de comunicação de todo o mundo para descrever a situação séria enfrentada na Síria.

Constatamos que: "A Anistia Internacional e outras organizações também documentaram violações do direito internacional humanitário e abusos de direitos humanos cometidos por grupos armados não estatais em Aleppo desde o início do conflito" (AMNESTY INTERNATIONAL, 2015, p. 11, tradução nossa). Tendo em vista a própria sobrevivência, os rebeldes do mesmo modo violam a dignidade humana, matando de maneira desregrada todo e qualquer apoiador do governo. Essas violações por meio da violência se encaixam como resposta aos ataques dizimadores que supliciavam a todos (AMNESTY INTERNATIONAL, 2015).

Diante do menosprezo pela vida e da desvalorização da dignidade da pessoa humana, corporificada pelo governo ditatorial, pelos rebeldes e financiada pelos aliados, podemos observar a repetição da estrutura de banalização denunciada por Arendt. Em Aleppo essa banalização ganhou grande evidência, revelando o seu lado estrutural. Para ela, o mal sempre existirá numa sociedade que despreza o outro ou só o reconhece como um adversário (ARENDT, 1999).

Os ataques violentos disseminam o mal que é empregado sem preocupação ou reflexão alguma. Pessoas inocentes são penalizadas por execuções e manifestações horrendas de pura maldade e crueldade (AMNESTY INTERNATIONAL, 2015), manipuladas e assassinadas como se já não fossem mais pessoas, mas simples objetos, joguetes na mão de um homicida. Além de conviver com a maldade e com o ódio puro, os civis presenciam rígidos ataques e severos bombardeios que os apresentam à fome, aos destroços e aos corpos dos parentes mortos e/ou mutilados, obrigando-os a viver sem perspectiva alguma de vida, exceto à espera do próximo ataque (ŽlŽEK, 2013). 
Interrogamo-nos a este ponto, mais uma vez, sobre os motivos que conduzem a essa banalização da vida humana diante de interesses tão escusos como os encontrados nesse conflito. Em dois momentos, Hannah Arendt contribui para encaminhar a reflexão a uma resposta. No primeiro caso, em "Eichmann" (1999), ao tratar da banalidade da vida humana transformada em números, planilhas e tabelas. No segundo caso, no seu "A Condição Humana" (2014), retoma a análise mais detalhada da instrumentalização da vida humana e da reificação da pessoa.

Ao retratar Eichmann como um mero cumpridor de leis e executor de ordens dadas por seu superior, Arendt o aponta como um autêntico exemplo de banalização do ser humano. Segundo a filósofa, o acusado alegou em sua defesa que "cumpria o seu dever [...] não só obedecia ordens, ele também obedecia à lei" (ARENDT, 1999, p. 152). Eichmann se relacionava com as ações que deveria executar, no que se referia à "questão judaica", de forma indiferente, indeterminada e inegociada. Tratava-as como um trabalho, sem dar muita atenção às implicações. Aquilo que era coordenado por Eichmann tinha impacto direto em vidas humanas; entretanto, do modo como ele encarava seu ofício, essas vidas eram descartadas com total indiferença.

O trabalho executado por Eichmann dentro do sistema do nazismo alemão consistia, basicamente, em organizar a separação dos judeus, dividindo aqueles que deveriam ser destinados ao extermínio e aqueles que seriam utilizados em trabalhos forçados (ARENDT, 1999). Nessa perspectiva, o acusado encarava os judeus como simples "artefatos" que estavam envolvidos na sua função prática. Arendt descreve o modo de pensar de Eichmann reafirmando que este não se sentia incomodado pelo fato de estar lidando com o destino de seres humanos: "Sua cabeça estava inteiramente tomada pelo gigantesco trabalho de organização e administração, não apenas em meio a uma guerra" (ARENDT, 1999, p. 168). Portanto as atitudes de Eichmann corroboram a ideia de instrumentalização da vida humana que tem por consequência a sua banalização, prejudicando a sua dignidade.

Ao descrever o processo de passagem do ser humano de uma condição de animal laborans para homo faber, Arendt afirma que ocorre uma instrumentalização dele. Na obra "A Condição Humana", a autora intui que, ao desenvolver habilidades de fabricação de produtos, especialmente após 
a Revolução Industrial, o sujeito humano passa a se encarar como uma engrenagem desse mecanismo de produção de coisas. Arendt aponta que a instrumentalização humana "implica a degradação de todas as coisas a meios, a perda do seu valor intrínseco e independente" (ARENDT, 2014, p. 195). Nessa lógica de reificação, também o ser humano se torna "coisa", objeto, podendo ter, assim, seus direitos questionados e sua dignidade ignorada.

Numa concepção antropológica utilitarista, o ser humano perde aqueles aspectos que o diferenciam dos demais seres, tornando-se algo que pode ser descartado ou substituído sem o menor prejuízo de consciência. Além disso, numa lógica fabril, a especificidade do ser humano não está mais naquilo que o constitui como tal, mas naquilo que é capaz de fabricar, produzir. Dessa maneira, o homem deixa de ser Dasein e trona-se "à mão" (ARENDT, 2014) e, como afirma Arendt, "em um mundo estritamente utilitário, todos os fins são constrangidos a serem de curta duração e a se transformarem em meios para alcançar outros fins" (ARENDT, 2014, p. 191-192). Ou seja, facilmente um ser humano pode deixar de ser um fim e se tornar um meio para atingir outras finalidades. É o que se percebe em situações de intolerância e guerra, como no tempo do nazismo alemão e como é hoje na Guerra Civil Síria.

Muitos são os fatos de pura crueldade que evidenciam o mal disseminado na guerra síria e possibilitam inferir que ela tem sido uma exemplificação do conceito de "banalidade do mal". Percebe-se que os rebeldes, em si, não são maus, mas, diante das circunstâncias enfrentadas, eles respondem de forma violenta aos ataques do governo, praticando o mal; da mesma forma o governo sírio, pois ele em si não é mal, mas, para se manter no poder, serve-se do mal e da violência (AMNESTY INTERNATIONAL, 2015).

Então, o mal é banal e pode ser realizado por qualquer ser humano. Os financiadores do conflito, do mesmo modo, podem não ser maus em si mesmos, mas, ao apoiar, patrocinar a guerra, eles estão praticando o mal por interesses políticos e econômicos. Na Síria, o mal se tornou banal e tem sido praticado pelo governo, rebeldes e apoiadores. É perceptível que tais envolvidos abriram mão dos valores éticos para defender os próprios interesses e, motivados pelo contexto em que estão inseridos, simplesmente abandonam a reflexão ética e têm atitudes de violência e agressão (ARENDT, 1999). 
É importante notarmos que o extermínio, diante de todo o exposto, é justamente quando se dá a morte e o fim das classes menos favorecidas. Na situação da Síria, o extermínio é evidente, porque acontece entre os iguais, de sírio contra sírio. Independentemente das partes, quem morre é o povo sírio. Daí se origina a preocupação com o extermínio do povo e a transformação da pessoa humana em objeto.

Ao se compreender que a vida humana pode ser instrumentalizada, tendo sua dignidade desprezada, e percebendo-se que o mal é realizado de forma banal, isto é, por qualquer pessoa, em qualquer situação, as consequências encontradas são desastrosas. Num contexto de guerra, como é o atual panorama sírio, essas duas realidades desembocam no extermínio. Na Síria, devido aos conflitos armados, o povo tem seu país e sua sociedade destruídos; a população se percebe violentada nas suas individualidades; e, em decorrência do grande número de mortes, vidas vão se perdendo e uma cultura é lançada no abismo do esquecimento.

\section{CONSIDERAÇÕES FINAIS}

Seguindo o pensamento de Amy Allen (2016), ao propor que o filósofo deve aprender a transformar o mundo, uma vez que, de pensar, já nos fartamos, apresentamos essas linhas para criticamente pensarmos nossa realidade tentando unir teoria e prática. Uma parte essencial percebida foi que tal união se dá de forma bem menos litigiosa quando serve para a morte, para a violência, para banalizar o mal, pois constatamos que nessas realidades as palavras se transformam em ações concretas e, por vezes, destruidoras.

Este artigo se apresentou como um convite à reflexão filosófica sobre a guerra civil na Síria, especialmente no tocante à degradação da dignidade humana e do aparente extermínio do povo sírio. Essas problemáticas surgem dos constantes e massacrantes confrontos que conotam uma verdadeira suspensão e negação da vida humana, transformando as pessoas em números e tratando-as como descartáveis e massificadas socialmente.

Os conflitos na Síria têm levado seu povo à morte, que é o que caracteriza o extermínio: as pessoas vão morrendo até que esse povo chegue ao 
fim. Com a negação notória da pluralidade, os seres humanos estão fugindo massivamente do país em busca de vida digna; essa fuga, para proteger a própria vida, também pode ser considerada um extermínio, porque, mesmo sobrevivendo fora da Síria, essas pessoas já perderam um pouco de sua origem e de suas raízes culturais, sendo obrigadas a adquirir hábitos e costumes das culturas em que forem acolhidas.

Em síntese, esta abordagem não nutriu o propósito de elaborar e/ou apontar saídas para a problemática da guerra síria e seus desdobramentos. Buscamos, pois, promover um estudo e suscitar questionamentos que possibilitem novas reflexões e novas pesquisas que aprofundem e defendam a dignidade humana como parte constitutiva do ser humano, protegendo os valores e os direitos essenciais da pessoa, não apenas pelo campo da política, mas como membros insubstituíveis e capazes de contribuir com sua singularidade na pluralidade da vida. Em Hannah Arendt, passamos a ver cada ser humano como um "Messias em potencial", pois cada pessoa tem em si as capacidades de marcar positivamente a humanidade; se a esses sujeitos, mortos e espoliados pela guerra, negamos essa potencialidade, negaremos a esperança de mudança que tanto almejamos em nosso mundo marcado pela violência e pelo descaso.

\section{REFERÊNCIAS}

ALLEN, Amy. The end of progress: decolonizing the normative foundations of critical theory. New York: Columbia University Press, 2016.

AMNESTY INTERNATIONAL. Death Everywhere - War crimes and human rights abuses in Aleppo, Syria. Amnesty Internacional, maio, 2015. Disponível em: https://www.amnesty.org/en/documents/mde24/1370/2015/en/. Acesso em: 23 abr. 2018.

ARENDT, Hannah. A condição humana. Rio de Janeiro: Forense Universitária, 2014.

ARENDT, Hannah. Sobre a violência. Rio de Janeiro: Civilização Brasileira, 2009.

ARENDT, Hannah. A promessa da política. Rio de Janeiro: DIFEL, 2008. 
ARENDT, Hannah. Origens do totalitarismo. São Paulo: Companhia das Letras, 2004.

ARENDT, Hannah. Eichmann em Jerusalém: um relato sobre a banalidade do mal. São Paulo: Companhia das Letras, 1999.

ARISTÓTELES. De Anima. Tradução de Maria Cecília Gomes dos Reis. São Paulo: Ed. 34, 2006.

DOUCET, Lyse. Sírios iniciam a difícil tarefa de reconstruir Aleppo. BBC News, São Paulo, fev. 2018. Disponível em: https://www.bbc.com/portuguese/ internacional-42926216\#orb-banner. Acesso em: 5 jul. 2018.

CRUZ-NETO, Otávio; MINAYO, Maria Cecília de S. Extermínio: violentação e banalização da vida. Cadernos de Saúde Pública, Rio de Janeiro, v. 10, supl. 1, 199-212, 1994.

KANT, Immanuel. A metafísica dos costumes. Lisboa: Fundação Calouste Gulbenkian, 2005.

KERSHAW, Ian. De volta ao inferno. São Paulo: Companhia das Letras, 2016.

LAFER, Celso. A reconstrução dos direitos humanos. São Paulo: Companhia das Letras, 2003.

ŽıŽEK, Slavoj. Violência. São Paulo: Boitempo Editorial, 2014.

ŽıŽEK, Slavoj. Alguém disse Totalitarismo? Cinco intervenções no (mau) uso de uma noção. São Paulo: Boitempo Editorial, 2013.

ONU. Conflito continua a ter consequências desastrosas para povo sírio. ONUBR, jun. 2017. Disponível em: https://nacoesunidas.org/conflitocontinua-a-ter-consequencias-desastrosas-para-povo-sirio-diz-comissaoda-onu/. Acesso em: 10 fev. 2018. 